Article

\title{
Corrosion Protection of Monel Alloy Coated with Graphene Quantum Dots Starts with a Surge
}

\author{
Charles Bopp and Kalathur Santhanam * (D) \\ School of Chemistry and Materials Science, Rochester Institute of Technology, Rochester, NY 14623, USA; \\ csb9445@rit.edu \\ * Correspondence: ksssch@rit.edu
}

Received: 9 August 2019; Accepted: 23 September 2019; Published: 30 September 2019

\begin{abstract}
There has been an active interest in protecting metals and alloys using graphene coating. The mechanism by which corrosion protection occurs has not been well understood as the couple involved are both good electron conductors. In this work, we demonstrate that Monel alloy coated with graphene quantum dots (GQD) changes the corrosion rate with a surge (increase) caused by the galvanic coupling of the two materials. This surge results in the protective layer formation on Monel to inhibit the corrosion. X-ray fluorescence spectrum of Monel (400) alloy showed the composition of it as $\mathrm{Ni}(67.05 \%)$ and $\mathrm{Cu}(29.42 \%)$. The Tafel experiments carried out in $\mathrm{NaCl}$ and $\mathrm{Na}_{2} \mathrm{SO}_{4}$ electrolytes showed an initial enhancement of the corrosion rate followed by a decrease upon successive polarizations. Monel coated with graphene oxide (an insulator) shows no initial enhancement of corrosion rate; the coated samples showed a lower corrosion rate in comparison to the uncoated samples. X-ray fluorescence, Fourier Transform spectroscopy (FTIR) and Raman imaging studies have been carried out for understanding this transformation. Distinct peaks due to $\mathrm{Ni}-\mathrm{O}$ stretching and Ni-O-H bending vibration were observed in the FTIR spectrum.
\end{abstract}

Keywords: corrosion; graphene; Tafel; X-ray fluorescence; Raman imaging; Fourier transform infrared spectroscopy; Monel; nickel hydroxide

\section{Introduction}

A Monel alloy is a solid-solution binary alloy predominantly composed of nickel and copper [1,2]. Based on Hume-Rothery rules, the formation of substitutional solid solution alloy requires that: (a) the atomic radius of the solvent and solute atoms should be less than $15 \%$, (b) the crystal structures should be similar, (c) electronegativity difference should be small and (d) the valences of the two atoms should preferably be the same. Monel alloy conforms to the above rules and hence performs well in several applications such as: (a) aerospace, (b) marine applications, (c) oil refining, and (d) musical instruments (bass strings). A number of different alloys with differing atomic compositions have been manufactured under ASTM numbers 400, 401, 404, 405 and 500. Monel alloy has an ultimate tensile strength of more than $440 \mathrm{MPa}$ and a relative elongation of about $25 \%$. Monel 400 has excellent weldability [3] and stability that enables its usage in the marine environment. For utilization of the alloy in the above applications, it is necessary to conform to its long-term stability against corrosion. It has a corrosion rate of about $59.38 \mathrm{~mm} / \mathrm{y}$ [4] in carbonate melts, and when aluminized it has a value of $1.43 \times 10^{-3} \mathrm{~mm} /$ year [5,6]. In hydrochloric acid medium, the corrosion of Monel decreased to $0.172 \mathrm{~mm} / \mathrm{y}$ from $2.11 \mathrm{~mm} / \mathrm{y}$ upon covering it with a monolayer of pyrrolidine dithiocarboxylate [7]. Several corrosion inhibitors have been adsorbed on Monel, and among them green corrosion inhibitors like sodium diethyl dithiocarbamates having a lone pair of electrons on their two sulfur atoms show strong adsorption on Monel [8]. The effect of hydrochloric acid concentration on the corrosion rate of Monel was reported by Mishra [9]. The corrosion resistance of Monel alloy at $923 \mathrm{~K}$ has been 
examined and was correlated to the metallic $\mathrm{Li}$ in the molten electrolyte [10]. Several inhibitors for the corrosion of Monel have been examined, and among them the extracts of Mespilus japonica, Ricinus communis L. and Vitis vinifera have been shown to be very effective [11]. Monel $\mathrm{K}$ alloy (containing Ti and $\mathrm{Al}$ ) has also been investigated under corrosive conditions and has been shown to have a lower corrosion rate than Monel (with no Ti and Al) [12]. Hot corrosion behavior of Monel has also been investigated [13]. The corrosion of Monel in aerated and deaerated sodium chloride solutions showed a higher corrosion rate in aerated solutions [14,15]. The Monel $\mathrm{K}$ alloy with $3 \% \mathrm{Al}$ addition has been shown to be protective for sea water corrosion [16].

A revolutionary material from graphite having unforeseen properties such as electrical and thermal conductivity was discovered by Geim et al. in 2004. This material is made of the single layer of graphene. The application of this material to corrosion protection has recently been explored as a protective agent for plasmonic devices [17] or steel [18], and has been considered to be a lot more effective than chromate-free anticorrosion technology. Graphene's excellent electrical conductivity and high surface area play an important role in its anticorrosion mechanism. However, a chemical vapor deposition method of making graphene has been demonstrated to have defects and the anticorrosion property of it has been reported [19]. As we currently understand it, the anti-corrosion mechanism provided by graphene can be explained by a combination of three processes. On the one hand, graphene coatings can make the path of permeating water more torturous. Second, because of the impermeability of pristine graphene, the coatings act as an excellent barrier to water, oxygen and other corrosive materials. Furthermore, graphene has a higher electrical conductivity than steel [20], nonetheless both are good conductors. With polymeric anticorrosion coatings, when the corrosion starts at the metal/coating interface, electrons generated by the anodic reaction move through the metal to a cathodic site for completing the corrosion reaction. This is the reason that, once the corrosion starts at the interface of the metal, it is difficult to stop the reaction. However, when functionalized graphene is incorporated in the coating, an alternative path for the electrons is provided, so that they may never reach a cathodic site. Moreover, graphene and graphene hybrid nanocomposites can be used as inhibitors in protective coatings [21-23] to prevent the oxidation of underlying metals in oxidizing chemicals, water or air for longer periods.

A galvanic coupling generally provides a protection to the coupled metal under ideal conditions [18] if the corroding metal stays active relative to the noble metal. We wish to report here the first instance of graphene forming a galvanic coupling with Monel that enhances the corrosion initially, resulting in Monel forming its hydroxide to break down the galvanic coupling, with the result that the corrosion rate drastically decreases to protect the alloy. The uniqueness of graphene in generating this transformation is discussed based on Tafel results.

\section{Experimental}

Chemicals: Sodium chloride ( $\mathrm{NaCl}$ ) [CAS No. 7647-14-5, ACS, 100 wt \%] and Sodium sulfate anhydrous [CAS 7757-82-6, ACS grade, 99.99\%] were procured from EMD Millipore Company. Graphene quantum dots were prepared as reported in the literature [24-27]. The sample conformed to the specifications of graphene given in the earlier publications from Raman spectrum, FTIR and UV-VIS spectrum. Graphene oxide (GO) prepared by Chemical Vapor Deposition Method was obtained from Graphene Square, Korea. Monel (area: $1.457 \mathrm{~cm}^{2}$ ) was placed in a GQD solution from one to $24 \mathrm{~h}$ to produce a thin ( $1 \mathrm{~h}$ coating) to thick ( $24 \mathrm{~h}$ coating) deposits of it on Monel. The deposit was washed with distilled water and used directly for polarization measurements. Some samples were annealed in the oven at $90{ }^{\circ} \mathrm{C}$ for $18 \mathrm{~h}$ after the coating. These samples were found to be converted to graphene oxide as the polarization behavior was similar to that of graphene oxide.

Instruments: X-ray fluorescence spectrometer; a Shimadzu EDX-8100 X-ray Fluorescence spectrometer was used for the elemental analysis. Fourier Infrared spectrometer (FTIR), a Shimadzu IR Prestige 21 was used for recording the spectrum. Raman spectrum was recorded using Bruker Optik Imaging spectrometer. 
Tafel Experiments: Ametek VersSTAT-4 Potentiostat/Galvanostat was used in all the experiments. Tafel software in VersSTAT-4 was used to collect the data and for analysis.

Electrodes: Monel electrode was degreased with isopropyl alcohol and later acid treatment was given. Counter electrode: Platinum coiled wire was used as the counter electrode. Reference Electrode: Gamry Saturated Calomel reference electrode was used.

Electrochemical Cell: Bob cell or a tall beaker with graduations fitted with Teflon cork was used for polarization measurements. The potentiodynamic curves were recorded for Monel alloy alone and with graphene covered samples. The polarization voltages ranged from $-0.20 \mathrm{~V}$ to $0 \mathrm{~V}$ vs. Saturated calomel electrode (SCE) with a step height of $9 \mathrm{mV}$ and step time of $3 \mathrm{~s}$. Electrochemical impedance spectroscopy (EIS) was carried out using $10 \mathrm{mV}$ (RMS) and a frequency of 0.001 to $1 \mathrm{kHz}$.

\section{Results and Discussion}

Table 1 shows the Energy dispersion X-ray analysis (EDAX) of the X-ray fluorescence spectrum.

Table 1. Energy Dispersion X-ray Analysis (EDAX) Analysis.

\begin{tabular}{ccc}
\hline Analyte & Percentage & Std. Dev \\
\hline $\mathrm{Ni}$ & 67.053 & 0.085 \\
$\mathrm{Cu}$ & 29.424 & 0.047 \\
$\mathrm{Fe}$ & 1.4740 & 0.009 \\
$\mathrm{Mn}$ & 1.0360 & 0.008 \\
$\mathrm{Cr}$ & 0.0461 & 0.006 \\
$\mathrm{Ca}$ & 0.1440 & 0.009 \\
$\mathrm{Si}$ & 0.1100 & 0.012 \\
\hline
\end{tabular}

(Figure 1) of Monel (400) that was used in the experiments. The spectral features were identical to the one reported in the literature for Monel (400) [28].

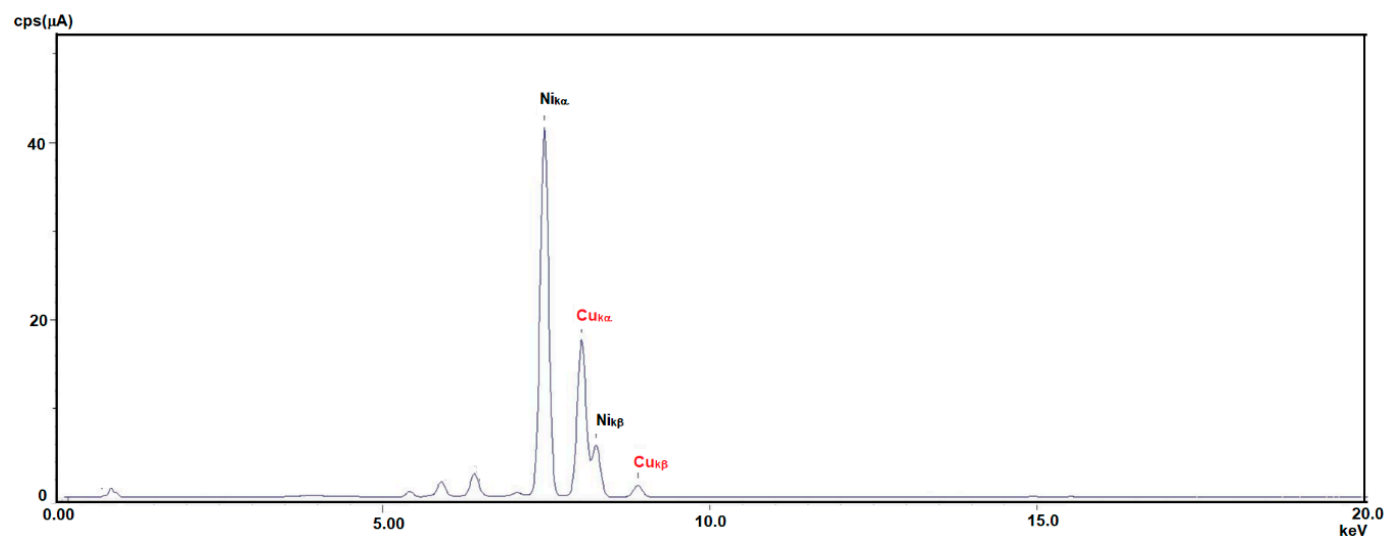

Figure 1. X-ray Flourescence (XRF) of Monel alloy used in the experiments.

\subsection{Monel Polarization Studies}

Monel alloy is treated with isopropyl alcohol for fifteen minutes to remove surface impurities and treated with acid for 5 to $15 \mathrm{~min}$ to clean the surface before running the potentiodynamic curves. Table 2 gives the medium employed, the measured corrosion densities, and the estimated corrosion rates. The corrosion rate is calculated using Equation (1) which is arrived at using Faraday's second law of electrolysis for the current flow occurring due to the corrosion reaction.

$$
\mathrm{k}_{\mathrm{corr}}=\left\{\mathrm{I}_{\mathrm{corr}} \mathrm{N}(\mathrm{EW}) / \rho\right\}
$$


where $\mathrm{k}_{\text {corr }}=$ corrosion rate, $\mathrm{I}_{\text {corr }}$ is the corrosion current density $\left(\mathrm{A} / \mathrm{cm}^{2}\right), \mathrm{N}$ is a constant value that relates to the units of corrosion rate $=3272 \mathrm{~mm} / \mathrm{y}$, EW is the equivalent weight of Monel, $\rho$ is the density $8.90\left(\mathrm{~g} / \mathrm{cm}^{3}\right)$ for Monel and A is the area of the sample. The data obtained show that there is a difference in the corrosion rates in $\mathrm{NaCl}$ and $\mathrm{Na}_{2} \mathrm{SO}_{4}$ media and falls in the expected behavior of faster rate of metal degradation in chloride medium [29]. The Monel alloy is coated with graphene quantum dots for different time durations before the polarization studies. Monel alloy coated with graphene used in the above experiments along with Raman imaging spectrum of the sample is shown in Figure 2. The appearance of $\mathrm{D}$ and $\mathrm{G}$ bands along with $2 \mathrm{D}$ band is indicative of the graphene adsorbed layer. The phonon mode (E2g symmetry) at the Brillouin zone center is doubly degenerate and caused the $\mathrm{G}$ band appearance. It is considered as a normal first order Raman scattering process in graphene. The other bands are caused by second order processes [30]. The 2D band is split instead of being a sharp peak due to the defects caused by the adsorption of graphene on Monel. Figure 2A exhibits the black coating color of graphene on a shiny monel surface. The dip coating of GQD is carried out for different durations before beginning the potentiodynamic experiments. The Tafel plots of Monel and Monel with graphene quantum dots are presented in Figure 3 for the $25 \mathrm{~h}$ deposition of GQD. Here the first polarization experiment showed a very high corrosion current compared to the subsequent ones. Thereafter, the corrosion currents are nearing a steady value. Table 3 gives the observed experimental results upon successive polarizations. The first polarization measurement of the $1 \mathrm{~h}$ GQD sample had a corrosion rate nearly 25 times as high as Monel alone. After three polarizations, however, the corrosion rate decreased to the value of uncoated Monel. The data obtained in the measurements with coated Monel shows that its corrosion rate is higher which decreases upon successive polarizations to the value of uncoated Monel. The observed features of GQD coated Monel is compared in Figure 4. This suggests that during the polarization measurements, the galvanically coupled Monel appears to undergo a transformation. Figure 4 also depicts the galvanic potentials of different metals and the state of the Monel alloy after the first polarization. Based on the galvanic series, graphene will be noble and Monel will be active suggesting the galvanic coupling of the metals. The breakdown of the galvanic coupling during the polarization results in the formation of hydroxides on the surface of Monel causing it to become a non-conductor (see FTIR section).

Table 2. Tafel analysis and corrosion rates.

\begin{tabular}{cccc}
\hline Treatment & Medium & $\mathbf{I}_{\text {corr }}\left(\mathbf{A} / \mathbf{c m}^{2}\right)$ & $\mathbf{K}_{\text {corr }}(\mathbf{m m} / \mathbf{y})$ \\
\hline None & $0.1 \mathrm{M} \mathrm{NaCl}$ & $3.11 \times 10^{-6}$ & 0.035 \\
None & $3.5 \mathrm{wt} \% \mathrm{NaCl}$ & $2.13 \times 10^{-6}$ & 0.024 \\
None & $0.1 \mathrm{M} \mathrm{Na}_{2} \mathrm{SO}_{4}$ & $7.25 \times 10^{-7}$ & 0.008 \\
$5 \mathrm{~min}$ & $0.1 \mathrm{M} \mathrm{NaCl}$ & $4.17 \times 10^{-7}$ & 0.005 \\
$5 \mathrm{~min}$ & $3.5 \mathrm{wt} \% \mathrm{NaCl}^{-6}$ & $1.02 \times 10^{-6}$ & 0.011 \\
$5 \mathrm{~min}$ & $0.1 \mathrm{M} \mathrm{Na}_{2} \mathrm{SO}_{4}$ & $5.78 \times 10^{-7}$ & 0.006 \\
$10 \mathrm{~min}$ & $0.1 \mathrm{M} \mathrm{NaCl}$ & $1.29 \times 10^{-6}$ & 0.014 \\
$10 \mathrm{~min}$ & $3.5 \mathrm{wt} \% \mathrm{NaCl}^{-6}$ & $1.60 \times 10^{-6}$ & 0.018 \\
$10 \mathrm{~min}$ & $0.1 \mathrm{M} \mathrm{Na}_{2} \mathrm{SO}_{4}$ & $5.36 \times 10^{-7}$ & 0.006 \\
$15 \mathrm{~min}$ & $0.1 \mathrm{M} \mathrm{NaCl}^{-6}$ & $1.21 \times 10^{-6}$ & 0.013 \\
$15 \mathrm{~min}$ & $3.5 \mathrm{wt} \% \mathrm{NaCl}^{-7}$ & $3.44 \times 10^{-7}$ & 0.004 \\
$15 \mathrm{~min}$ & $0.1 \mathrm{M} \mathrm{Na}_{2} \mathrm{SO}_{4}$ & $1.84 \times 10^{-6}$ & 0.021 \\
\hline
\end{tabular}




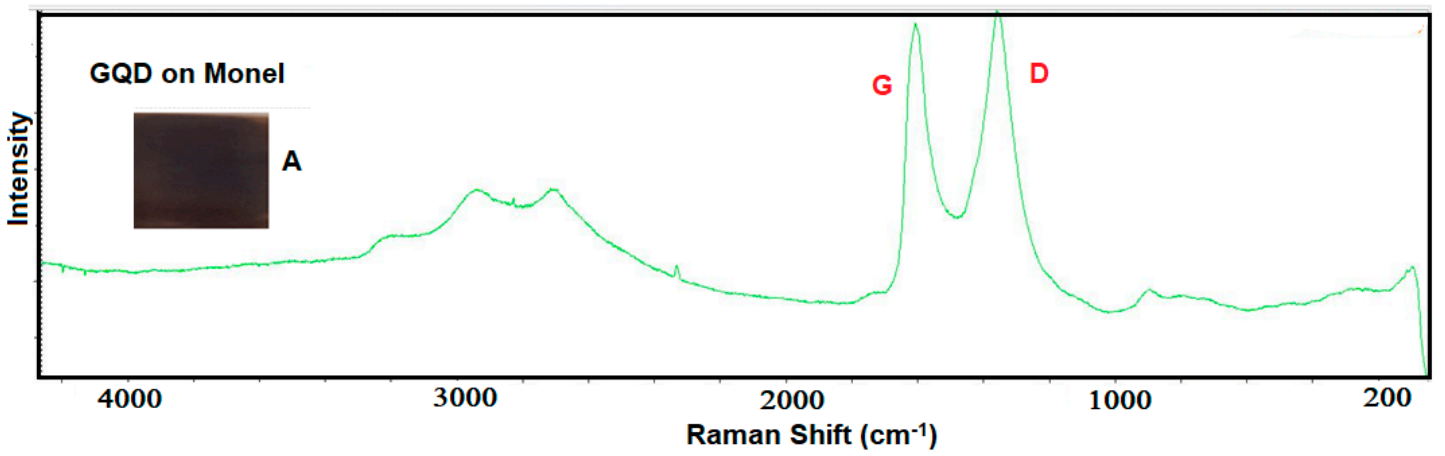

Figure 2. An optical image of Monel coated graphene quantum dots. Raman spectrum of the Monel adsorbed graphene quantum dots.

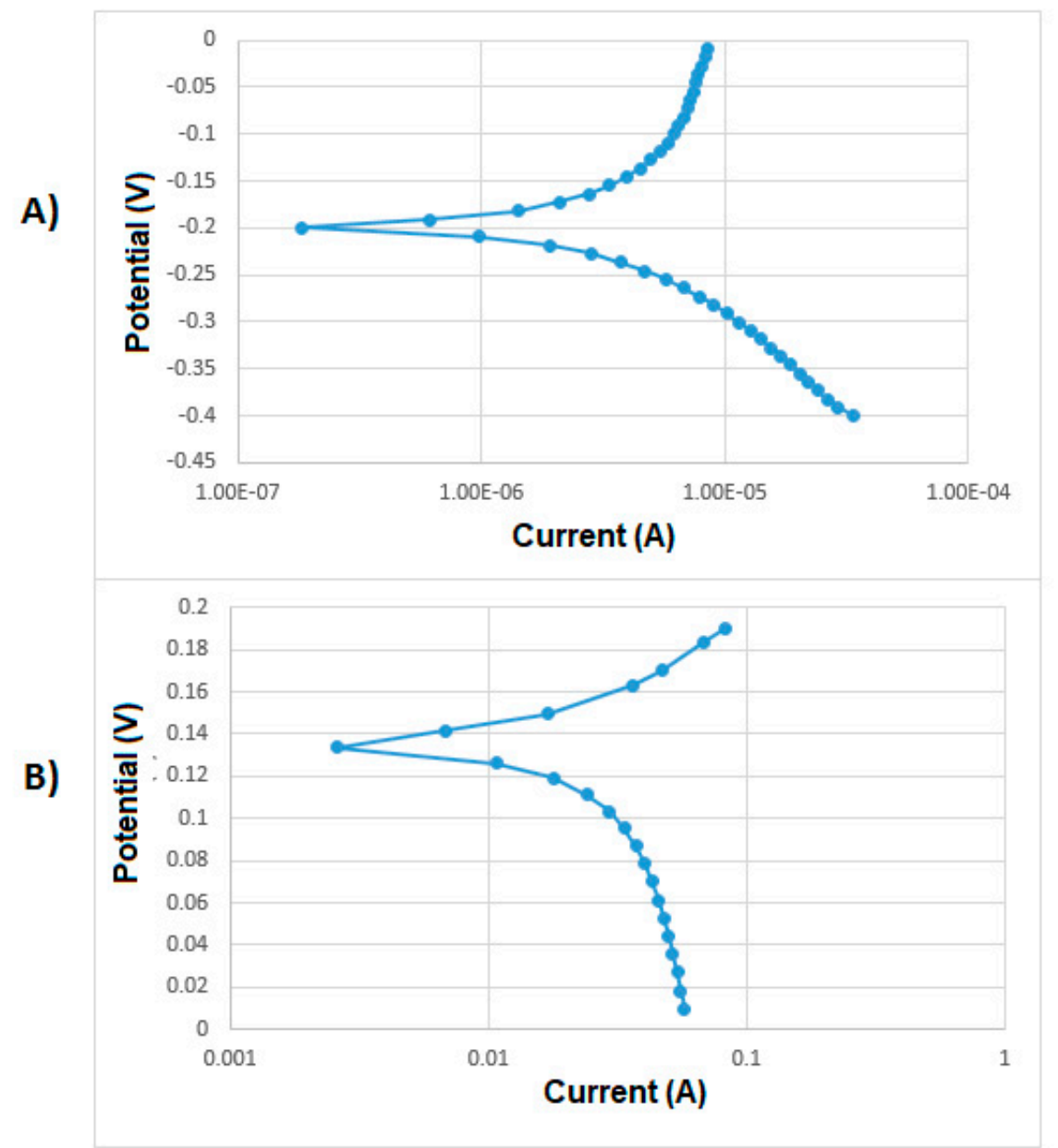

Figure 3. Tafel plot and analysis of (A) Monel (400) and (B) Monel coated with graphene quantum dots for $25 \mathrm{~h}$. Potential is referred with SCE. Medium: $0.1 \mathrm{M} \mathrm{NaCl}$. 
Table 3. Tafel analysis of Monel coated graphene.

\begin{tabular}{cccc}
\hline Treatment Duration & Polarization Number & $\mathbf{I}_{\text {corr }} \mathbf{( A / \mathbf { c m } ^ { \mathbf { 2 } } )}$ & $\mathbf{k}_{\text {corr }} \mathbf{( \mathbf { m m } / \mathbf { y } )}$ \\
\hline $1 \mathrm{~h}$ & 1 & $2.89 \times 10^{-5}$ & 0.322 \\
$1 \mathrm{~h}$ & 2 & $3.24 \times 10^{-6}$ & 0.036 \\
$1 \mathrm{~h}$ & 3 & $1.21 \times 10^{-6}$ & 0.014 \\
$25 \mathrm{~h}$ & 1 & $6.06 \times 10^{-3}$ & 67.68 \\
$25 \mathrm{~h}$ & 2 & $4.69 \times 10^{-7}$ & 0.005 \\
$25 \mathrm{~h}$ & 3 & $3.78 \times 10^{-7}$ & 0.004 \\
$25 \mathrm{~h}$ & 4 & $3.94 \times 10^{-7}$ & 0.004 \\
$25 \mathrm{~h}$ & 5 & $4.80 \times 10^{-7}$ & 0.005 \\
$25 \mathrm{~h}$ & 6 & $4.36 \times 10^{-7}$ & 0.005 \\
\hline
\end{tabular}

\section{Galvanic series}

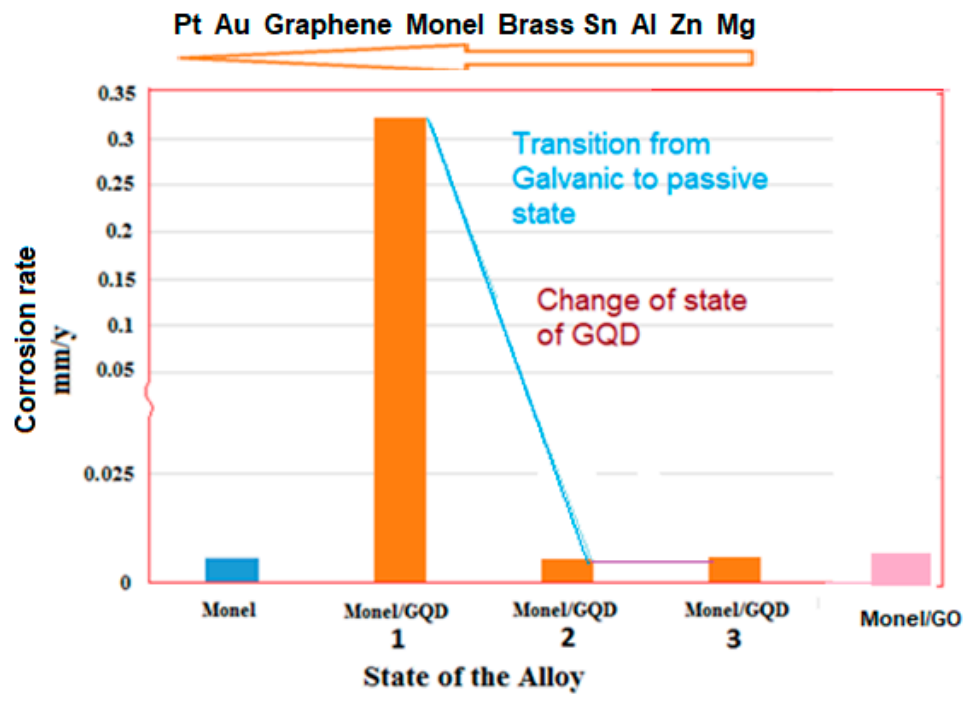

Figure 4. Monel alloy corrosion rates with coatings; 1, 2, 3 represent the polarization measurements.

\subsection{Monel Coated with Graphene Oxide}

The experiments with Monel coated graphene oxide showed a slightly higher corrosion current density value than the uncoated Monel in the polarization experiments. We did not observe a high corrosion density in the first polarization as observed with GQD coatings. This was a contrasting behavior of the oxide coating. The CVD method of making graphene is discussed in the literature to have defect centers [19]. The data obtained from Tafel analysis is presented in Table 4 . Figure 4 shows the corrosion rate obtained with GO coating. Since there has been no change in the corrosion rates from first to successive polarizations, only one value is shown in the figure.

Table 4. Tafel plot analysis Monel coated with graphene oxide.

\begin{tabular}{cccccc}
\hline Electrode & Area $\left(\mathbf{c m}^{\mathbf{2}}\right)$ & $\mathbf{E}_{\mathbf{c o r r}}(\mathbf{m V})$ & $\mathbf{I}_{\text {corr }}(\boldsymbol{\mu A})$ & $\mathbf{I}_{\text {corr }}\left(\boldsymbol{\mu A} \mathbf{A} \mathbf{c m}^{\mathbf{2}}\right)$ & $\mathbf{k}_{\text {corr }}(\mathbf{m m} / \mathbf{y})$ \\
\hline Monel-Graphene oxide & 2.897 & -139.1 & 4.908 & 1.694 & 0.0378 \\
Monel-Graphene oxide & 2.897 & -141.5 & 4.348 & 1.501 & 0.0335 \\
\hline
\end{tabular}

Medium: $0.1 \mathrm{M} \mathrm{NaCl}$.

FTIR Spectrum: The sample of Monel coated with graphene quantum dots is analyzed by FTIR after successive potentiodynamic experiments. Figure 5 shows the FTIR spectrum with vibrational 
peaks at $3458 \mathrm{~cm}^{-1}$ due to $\mathrm{OH}$ stretch, and peaks at $405 \mathrm{~cm}^{-1}$ and $582 \mathrm{~cm}^{-1}$ due to Ni-O stretching and $\mathrm{Ni}-\mathrm{O}-\mathrm{H}$, and bending vibration at $1688 \mathrm{~cm}^{-1}$ [31,32]. The sample developed slight green coloration. The experiments carried out under identical conditions with FTIR on blank Monel does not show the peak at $3458 \mathrm{~cm}^{-1}$, confirming that it is due to the hydroxide formation by corrosion reaction. We carried out chronoamperometric measurements on Monel coated GQD [33] and observed the green color development on the sample.

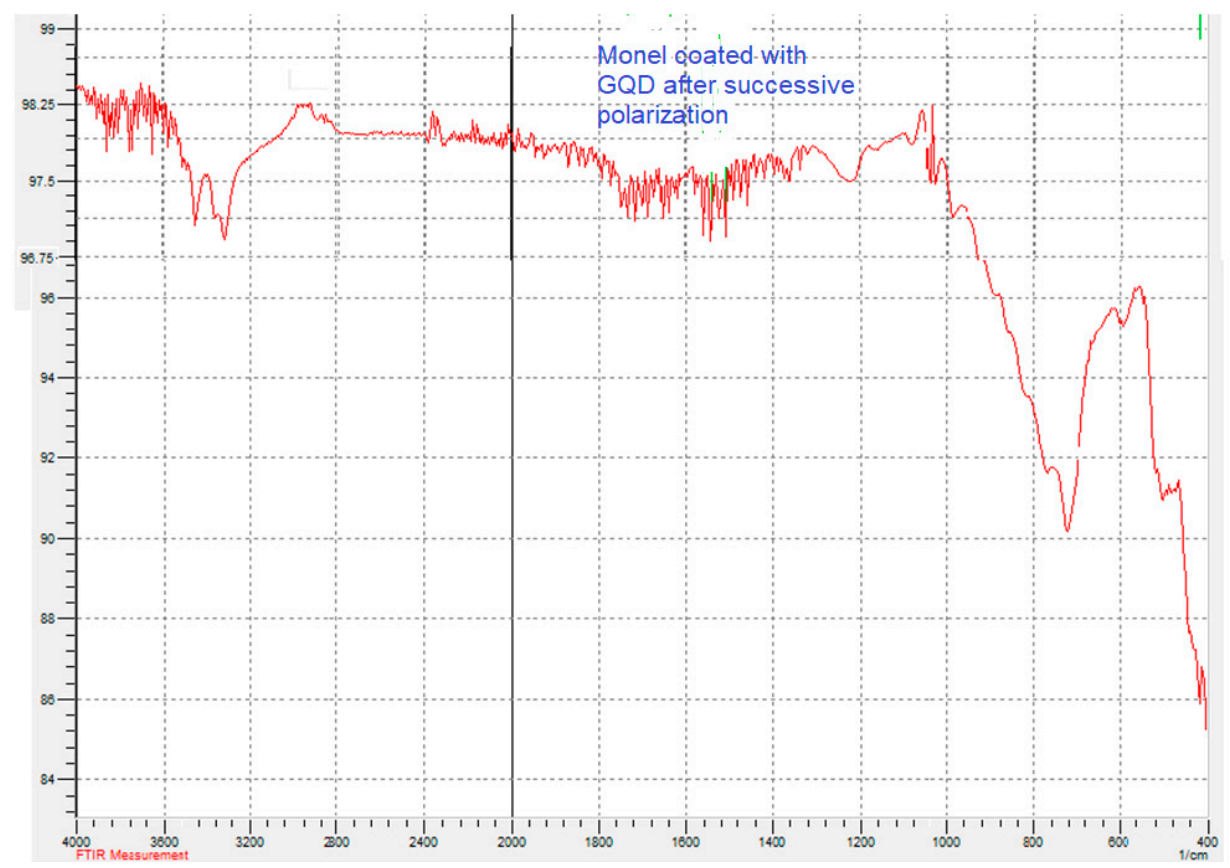

Figure 5. FTIR spectrum of Monel coated with graphene upon successive polarizations.

\subsection{Electrochemical Impedance Spectroscopy}

Electrochemical impedance spectroscopy (EIS) is a very useful technique for obtaining resistive behavior of surface/electrolyte interface and can be used to study the protective films on metals. The common representation of the EIS is the plot of $Z_{\text {imaginary }}$ vs. $Z_{\text {real, }}$ often called the Nyquist plot, which provides the processes at various interfaces. In order to understand the mechanism operating in the corrosion of Monel coated with GQD, EIS was used. Here, a small sinusoidal perturbation was applied to the electrochemical cell and the impedance modulus was recorded as a function of frequency, $\omega$. A plot of real and imaginary impedance modulus was generated to determine the mechanism and robustness of the coating. The observed behavior was understood by fitting the data to a simple equivalent circuit model. Figure 6 shows the Nyquist plot for the Monel coated with GQD. The $R_{p}$ value measured is $421.26 \mathrm{ohm} \mathrm{s} / \mathrm{cm}^{2}$ for the first polarization, which increased upon subsequent polarizations. This is consistent with the results obtained from Tafel plots (see Table 3 where the corrosion densities changing from polarization). The Bode's plot shown in Figure 7 shows the same trend of increased polarization resistance in subsequent polarizations, again consistent with Nyquist results. The $R_{p}$ value measured with Monel/GQD is a lot lower than has been reported for $\mathrm{Cu} / g r a p h e n e$, suggesting that Monel/graphene is better coupled to give a lower $R_{p}$ value. In a typical case of an insulating material coated on a metal such as copper [34], this value is $4.2 \mathrm{M} \Omega / \mathrm{cm}^{2} / \mathrm{CH}_{2}$ group when copper is coated with n-alkane thiols by varying the number of $\mathrm{CH}_{2}$ groups. The Monel coated GQD was showing a lower polarization resistance indicating higher corrosion current which decreases with number of polarizations due to the formation of insulating film on Monel. 

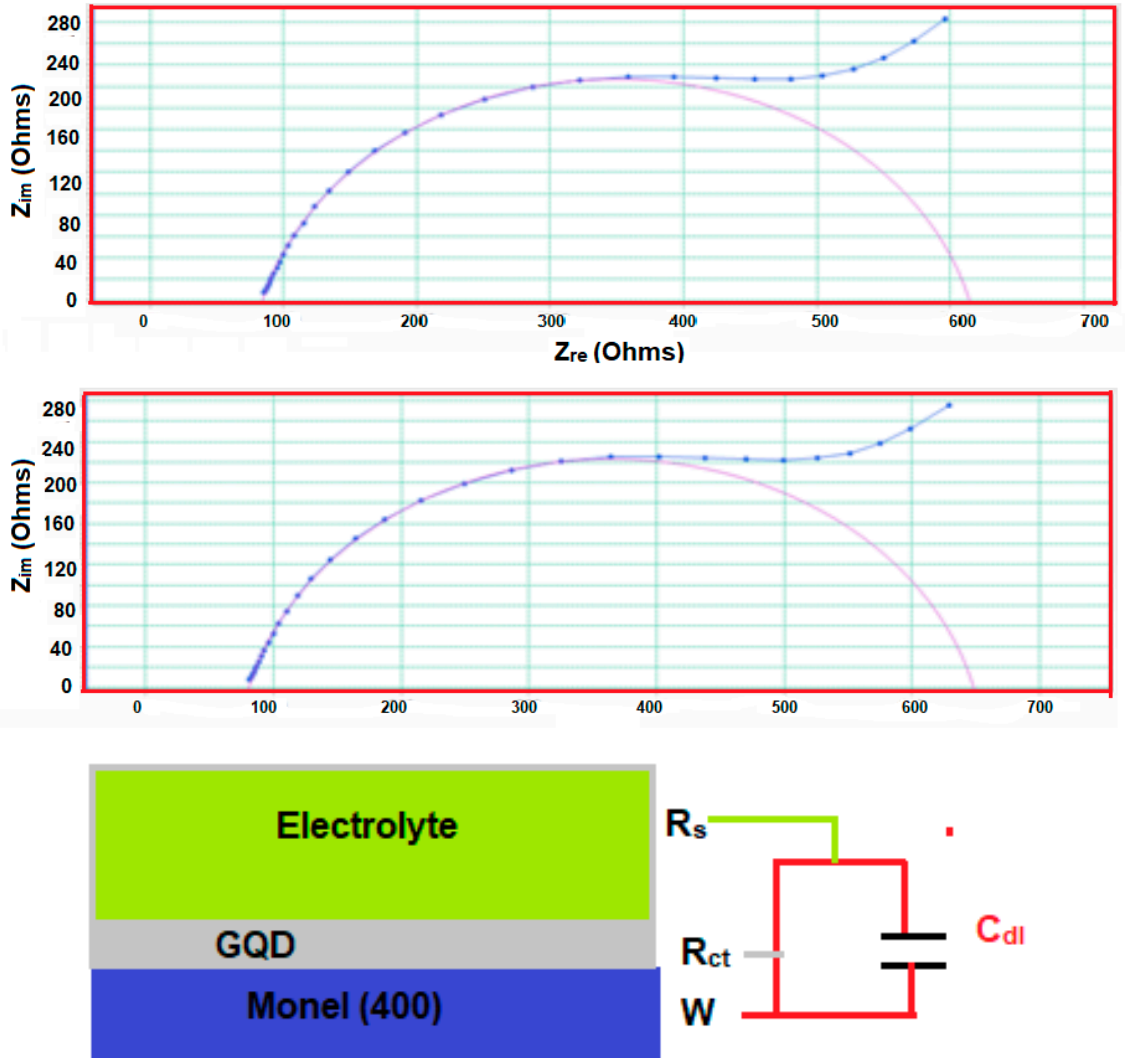

Figure 6. Nyquist plot for the Monel coated with Graphene quantum dots (GQD). Upper curve represents first run and bottom curve represents after Tafel polarization. Equivalent circuit is given at the bottom.
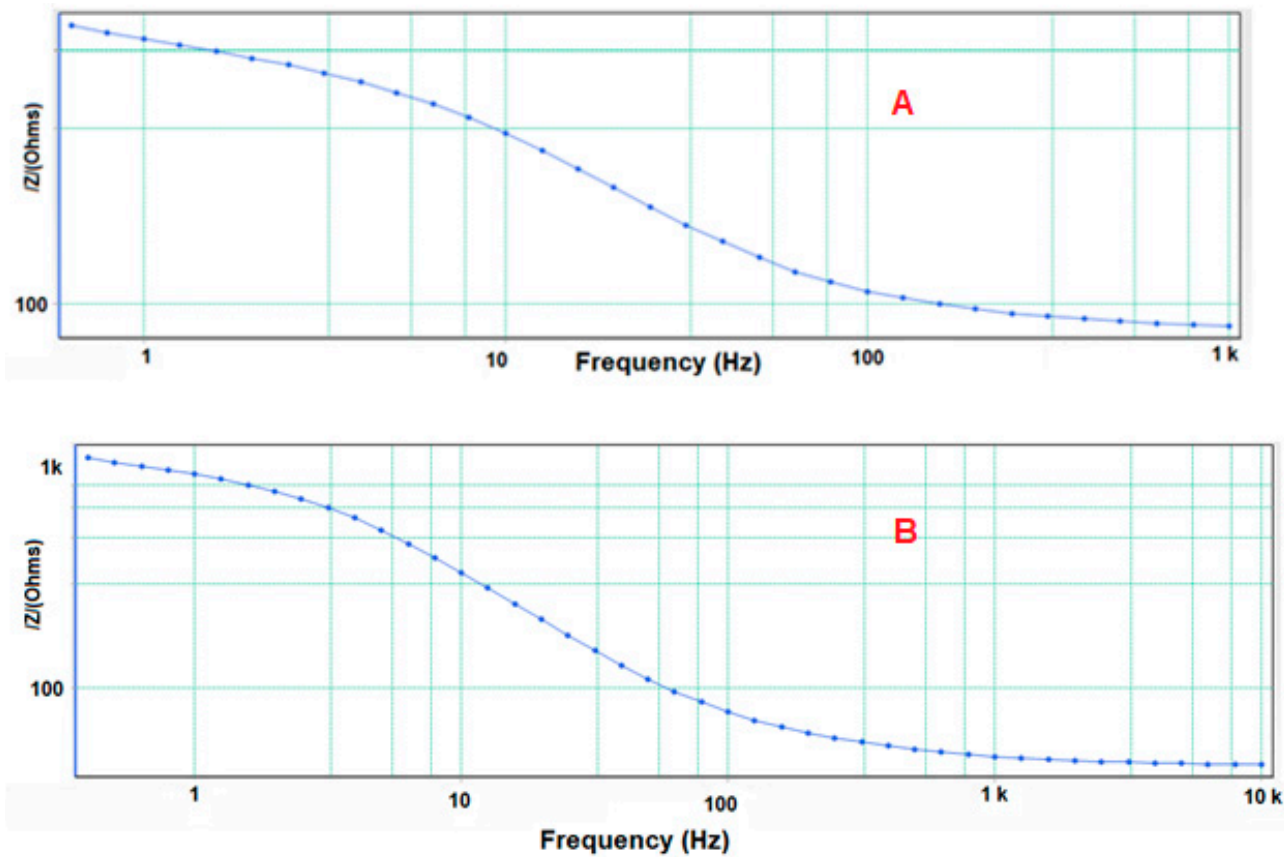

Figure 7. Bode's plot of impedance vs. frequency for Monel coated with GQD for $45 \mathrm{~h}$. (A) First measurement; (B) subsequent measurement. 


\subsection{Mechanism of Corrosion}

Monel alloy has an electrical resistivity of $54.7 \times 10^{-8} \mathrm{ohm} \mathrm{m}$ and is comparable to that of platinum $\left(10.5 \times 10^{-8} \mathrm{ohm} \mathrm{m}\right)$. It is a nickel-cupro alloy that has been used extensively in technological applications. Graphene is a 2D material with an electrical resistivity of $10^{-6} \mathrm{ohm} \mathrm{m}[35,36]$, lower than silver $\left(1.59 \times 10^{-8} \mathrm{ohm} \mathrm{m}\right)$. Based on the known values of electrical resistivity of Monel and graphene, the two materials fall into the class of metals whose resistivity are in the range of $10^{-7}$ to $10^{-8} \mathrm{ohm} \mathrm{m}$ [36]. A Monel alloy coated with graphene now falls into the category of two dissimilar metals in contact, and when the coupled metals are in a conducting electrolyte it fulfills the conditions for galvanic corrosion, if the standard potentials of Monel and graphene are not identical [29]. Figure 5 shows the galvanic series of metals of interest based on their standard potentials [37,38]; the arrow indicates the increasing potential values. Monel metal has high Ni content and hence its potential falls closer to that of Ni. Monel metal is active as its potential is less than graphene based on the above galvanic series. By coupling Monel with graphene, all the desirable requirements are fulfilled for galvanic corrosion. Two step galvanic corrosion is possible.

Step 1 (Graphene/Monel)

In the above combination (Monel and graphene), Monel alloy would be expected to be oxidized, with the electron transported to graphene where oxygen in the medium would be reduced on graphene followed by the hydroxide ion transported to Monel alloy, resulting in the formation of the metal hydroxide by the following mechanism. Since Monel 400 comprises more of nickel atoms (often Monel is called a nickel alloy), it is likely to form nickel hydroxide as corrosion progresses. At this stage step 2 will overtake step 1.

$$
\begin{gathered}
\mathrm{M} \rightarrow \mathrm{M}^{2+}+2 \mathrm{e}^{-}(\mathrm{M}=\text { Monel alloy }) \\
\left.\mathrm{H}_{2} \mathrm{O}+2 \mathrm{e}^{-}+1 / 2 \mathrm{O}_{2}=2 \mathrm{OH}^{-} \text {(Graphene }\right)
\end{gathered}
$$

Overall

$$
\mathrm{M}+\mathrm{H}_{2} \mathrm{O}+1 / 2 \mathrm{O}_{2}=\mathrm{M}(\mathrm{OH})_{2}
$$

Step 2 Passivation (Protection)

The galvanically poised corrosion of Monel coupled graphene can be transformed to a passivating layer formed on Monel by the hydroxide. This may be represented as graphene//M(OH $)_{2} / \mathrm{Monel}$ with the graphene metal-covered Monel filled with the hydroxide resulting in a configuration where an electrical conductor is in contact with an insulator. This situation will be a long-lasting one in the protection of Monel alloy.

Consider a situation of Monel coated with a non-conducting material such as graphene oxide where $\mathrm{sp}^{2}$ bonding is disrupted, providing a situation where it is protected with a barrier material. In such a situation, Monel alloy is protected by a conventional mechanism [37] by limiting the flow of oxygen and moisture. In this case, the protection follows step 2 described earlier. The following experiments are carried out in the search for the operating mechanism in the Monel alloy.

Of the two materials examined for the corrosion protection of Monel, GQD is an electrical conductor and GO is electrically an insulator. The Monel coated GQD falls into the category of a galvanically coupled system, which is generally expected to behave as a protector or insulator based on the galvanic potentials of the couples [36-39]. The electrode potentials are a relative measure of a metal's ability to be active in a selected electrolyte. Monel forms the anode (positively charged electrode) in an electrolyte; the less noble metal is likely to act as the cathode (negatively charged electrode). The metal ions move from the anode to the cathode. Hence, in this situation as discussed in step 1, the Monel forms the hydroxide on its surface resulting in the breakdown of galvanic coupling. The Monel hydroxide is not an electrical conductor and constitutes a situation of that depicted in step 2. Thus, a galvanically coupled pair experiences a surge in the corrosion rate of $0.032 \mathrm{~mm} / \mathrm{y}$ to $67.68 \mathrm{~mm} / \mathrm{y}$. 
The extent of surge depends on reaction [2] discussed earlier as it introduces the hydroxide on Monel. Consequently, the corrosion rate upon second polarization goes to a low value (from $67.68 \mathrm{~mm} / \mathrm{y}$ to $0.035 \mathrm{~mm} / \mathrm{y}$ ). When Monel alloy gets the coating, the behavior turns to be that of an insulator coating with GQD restricting the supply of oxygen for the corrosion reaction. Monel coated with GO conforms to the situation shown in step 2. Hence, in the Monel coating with GO, it is equivalent to an insulating coating for the supply of active ingredients. We do not observe a surge in corrosion with GO (Table 4).

\section{Conclusions}

It is shown that graphene coating on Monel initially enhances the corrosion rate because of galvanic coupling of the metals that is followed by corrosion inhibition due to the formation of the metal hydroxides. The corrosion rate of Monel is enhanced from $0.035 \mathrm{~mm} / \mathrm{y}$ to $67.68 \mathrm{~mm} / \mathrm{y}$ upon graphene coating. After successive polarizations, the corrosion rate drops down to $0.005 \mathrm{~mm} / \mathrm{y}$.

Monel coated with GO showed a corrosion rate of $0.037 \mathrm{~mm} / \mathrm{y}$. Raman spectrum of Monel coated graphene showed distinct D and G bands. FTIR spectrum of the Monel/graphene showed distinct peaks due to $\mathrm{OH}$ stretch, Ni-O and Ni-O-H in the regions of $3458 \mathrm{~cm}^{-1}, 405 \mathrm{~cm}^{-1}$ and $582 \mathrm{~cm}^{-1}$. The $\mathrm{R}_{\mathrm{p}}$ value measured from Nyquist plot for Monel/graphene is considerably lower than $\mathrm{Cu} / \mathrm{graphene.} \mathrm{Monel}$ alloy protection by GQD arises after an initial high rate of corrosion that is followed by passivation.

Author Contributions: C.B. carried out the experiments along with K.S. The latter proposed the project and planned the experiments. The results were jointly interpreted by us.

Funding: The project was carried out as an offshoot of the National Science Foundation grant award number (1604893) in search for stable metal supports for sensors.

Acknowledgments: One of the authors (KSVS) thanks the National Science Foundation for their financial support. The authors thank Byung Hee Hong (Graphene Square) for gifting a sample of GO and T. Allston for help with the XRF and Raman imaging.

Conflicts of Interest: The authors declare no conflict of interest.

\section{References}

1. Bhaduri, A. Mechanical Properties and Working of Metals and Alloys; Springer: Singapore, 2018; ISBN 978-981-10-7209-3.

2. Special Metals. Available online: http://www.specialmetals.com/assets/smc/documents/alloys/Monel/Monelalloy-400.pdf (accessed on 20 March 2019).

3. Ramkumar, K.D.; Joshi, V.; Pandit, S.; Agrawal, M.; Kumar, O.S.; Periwal, S.; Manikandan, M.; Arivazhagan, N. Investigations on the microstructure and mechanical properties of multi- pass pulsed current gas tungsten arc weldments of Monel 400 and Hastelloy C276. Mater. Des. 2014, 64, 775-782. [CrossRef]

4. Nikitina, E.V.; Kazakovtseva, N.A.; Maikov, M.A.; Malkov, V.B.; Karfidov, E.A.; Chuikin, A.Y. Electrochemical Corrosion Behavior of Monel Alloy in Carbonate Melts. Russ. J. Electrochem. 2018, 54, 697-698. [CrossRef]

5. Ma, F.Y.; Gao, F.; Zeng, Z. Improving the tribocorrosion resistance of Monel 400 alloy by aluminizing surface modification. J. Mater. Eng. Perform. 2018, 27, 3439-3440. [CrossRef]

6. Zhan, J.Z.; Li, J.; Lu, Y.J.; Wu, L.Q.; Zhao, N.Y. Technics and performance analysis of Monel alloy coating prepared by high velocity arc spraying. Mater. Res. Innov. 2013, 17, s112-s114. [CrossRef]

7. Bagherzadeh, M.; Jaberinia, F. Electrochemical study of Monel alloy corrosion in hydrochloric acid solution and pyrrolidine dithiocarboxylate self-assembled monolayers as its corrosion protector. J. Alloy. Compd. 2018, 750, 677679. [CrossRef]

8. Aljinović, L.; Gudić, S.; Šmith, M. Inhibition of CuNi10Fe corrosion in seawater by sodium-diethyl-dithiocarbamate: An electrochemical and analytical study. J. Appl. Electrochem. 2000, 30, 973-979. [CrossRef]

9. Mishra, A. Corrosion Study of Base Material and Welds of a Ni-Cr-Mo-W Alloy. Acta Metall. Sin. (Engl. Lett.) 2017, 30, 326-332. [CrossRef]

10. Phillips, W.; Merwin, A.; Chidambaram, D. On the Corrosion Performance of Monel 400 in Molten LiCl-Li 2 O-Li at 923 K. Metall. Mater. Trans. A 2018, 49, 2384. [CrossRef] 
11. Kherraf, S.; Zouaoui, E.; Medjram, M.S. Corrosion inhibition of Monel 400 in hydrochloric solution by some green leaves. Anti Corros. Methods Mater. 2017, 64, 347. [CrossRef]

12. Jun, C. Corrosion wear characteristics of TC4, 316 stainless steel, and Monel K500 in artificial Seawater. RSC Adv. 2017, 7, 23835-23845. [CrossRef]

13. Ramkumar, K.D.; Arivazhagan, N.; Narayanan, S.; Mishra, D. Hot Corrosion Behavior of Monel 400 and AISI 304 Dissimilar Weldments Exposed in the Molten Salt Environment Containing $\mathrm{Na}_{2} \mathrm{SO}_{4}+60 \% \mathrm{~V}_{2} \mathrm{O}_{5}$ at $600^{\circ}$ C. Mater. Res. 2014, 17, 1273-1284. [CrossRef]

14. Sherif, E.M.; Almajid, A.A.; Bairamov, A.K.; Al-Zahrani, E. A comparative Study on the Corrosion of Monel-400 in Aerated and Deaerated Arabian Gulf Water and 3.5\% Sodium Chloride Solutions. J. Electrochem. Sci. 2012, 7, 2796-2810.

15. Alar, V.; Stojanović, I.; Židov, B.; Ivušić, F. Corrosion Resistance of Highly Alloyed Materials in $3.5 \% \mathrm{NaCl}$ Solution at Elevated Temperature. Int. J. Electrochem. Sci. 2013, 8, 12477.

16. Wang, F.; Zhang, J.; Zou, J.T.; Fan, Z.K.; Zhang, F.S. Effects of Al contents on microstructure and properties of monel alloys. Metal Mater. Eng. 2010, 39, 1933-1937.

17. Kravets, V.G.; Jalil, R.; Kim, Y.-J.; Ansell, D.; Aznakayeva, D.E.; Thackray, B.; Britnell, L.; Belle, B.D.; Withers, F.; Radko, I.P.; et al. Graphene-protected copper and silver plasmonics. Sci. Rep. 2014, 4, 5517. [CrossRef] [PubMed]

18. Böhm, S. Graphene against corrosion. Nat. Nanotechnol. 2014, 9, 741-742. [CrossRef] [PubMed]

19. Lei, J.; Hu, Y.; Liu, Z.; Cheng, G.J.; Zhao, K. Defects Mediated Corrosion in Graphene Coating Layer Defects Mediated Corrosion in Graphene Coating Layer. ACS Appl. Mater. Interfaces 2017, 9, 11902-11908. [CrossRef]

20. Hu, J.; Ji, Y.; Shi, Y.; Hui, F.; Duan, H.; Lanza, M. A Review on the Use of Graphene as a Protective Coating against Corrosion. Ann. Mater. Sci. Eng. 2015, 1, 16.

21. Shen, L.; Li, Y.; Zhao, W.; Miao, L.; Xie, W.; Lu, H.; Wang, K. Corrosion Protection of Graphene-Modified Zinc-Rich Epoxy Coatings in Dilute NaCl Solution. ACS Appl. Nano Mater. 2019, 2, 180-190. [CrossRef]

22. Jayakumar, N.; Veedu, K.K.; Gopalan, N.K. Durable Hydrophobic Coating Based on Cerium Phosphate Nanorod Siliconized Epoxy for Corrosion Protection. ACS Appl. Nano Mater. 2019, 2, 2689-2696. [CrossRef]

23. Liu, C.; Du, P.; Zhao, H.; Wang, L. Synthesis of L-Histidine-Attached Graphene Nanomaterials and Their Application for Steel Protection. ACS Appl. Nano Mater. 2018, 1, 1385-1395. [CrossRef]

24. Santhanam, K.S.V.; Kandlikar, S.; Valentina, M.; Yang, Y. Electrochemical Process for Producing Graphene, Graphene Oxide, Metal Composites and Coated Substrates. US Patent 9,840,782, 12 December 2017.

25. Wong, P.; Santhanam, K.S.V.; Kandlikar, S. Cobalt Deposition from graphene quantum dot bath: Electrochemical and Spectroscopic Features-A Prospective Sensor Material. J. Electrochem. Soc. 2018, 165, B232. [CrossRef]

26. Protich, Z.; Wong, P.; Santhanam, K.S.V. A new graphene composite with a high coulombic efficiency. J. Power Sources 2016, 332, 337-344. [CrossRef]

27. Cusati, T.; Fiori, G.; Gahoi, A.; Passi, V.; Lemme, M.C.; Fortunelli, A.; Lannaccone, G. Electrical properties of graphene-metal contacts. Sci. Rep. 2017, 7, 5109. [CrossRef] [PubMed]

28. Khalid, N.; Wasim, M. Performance evaluation of $k_{0}$-instrumental neutron activation analysis and flame atomic absorption spectrophotometry in the characterization of various types of alloys. J. Radioanal. Nucl. Chem. 2013, 297, 153-159. [CrossRef]

29. Uhlig, H.H.; Revie, R.W. Corrosion and Its Control; Wiley: Hoboken, NJ, USA, 2010.

30. Malar, L.M.; Piment, M.A.; Dresselhaus, G.; Dresselhaus, M.S. Raman spectroscopy in Graphene. Phys. Rep. 2009, 473, 51-87. [CrossRef]

31. Budipramana, Y.; Ersam, S.T.; Kurniawan, F. Synthesis nickel hydroxide by electrolysis at high voltage. ARPN J. Eng. Appl. Sci. 2014, 9, 2074.

32. Khan, Y.; Durrani, S.K.; Mehmood, M.; Jan, A.; Abbasi, M.A. pH-dependant structural and morphology evolution of $\mathrm{Ni}(\mathrm{OH})_{2}$ nanostructures and their morphology retention upon thermal annealing to $\mathrm{NiO}$. Mater. Chem. Phys. 2011, 130, 1169-1174. [CrossRef]

33. Shearer, C.J.; Slattery, A.D.; Stapleton, A.J.; Shapter, J.G.; Gibson, C.T. Accurate thickness measurement of graphene. Nanotechnology 2016, 29, 125704. [CrossRef]

34. Jennings, G.K.; Munro, J.C.; Yong, T.H.; Laibinis, P.E. Effect of Chain Length on the Protection of Copper by n-Alkanethiols. Langmuir 1998, 14, 6130-6139. [CrossRef] 
35. Zhu, H.; Xu, Z.; Xie, D.; Fang, Y. Graphene: Fabrication, Characterizations, Properties and Applications; Academic Press: London, UK, 2018.

36. Rossiter, P.L.; Bass, J. The Electrical Resistivity of Metals and Alloys. Phys. Today 1988, 41, 78. [CrossRef]

37. Roberge, P.R. Corrosion Engineering: Principles and Practice; McGraw-Hill Education: Boston, MA, USA, 2008.

38. Santhanam, K.S.V.; Press, R.; Miri, M.; Bailey, A.; Takacs, G. Introduction to Hydrogen Technology, 2nd ed.; Wiley: Hoboken, NJ, USA, 2018.

39. Bard, A.J.; Faulkner, L.R. Electrochemical Methods; Wiley: Hoboken, NJ, USA, 2001.

(C) 2019 by the authors. Licensee MDPI, Basel, Switzerland. This article is an open access article distributed under the terms and conditions of the Creative Commons Attribution (CC BY) license (http://creativecommons.org/licenses/by/4.0/). 